\title{
Dissociative electron attachment to methylacetylene and dimethylacetylene: Symmetry versus proximity
}

\author{
R. Janečková, O. May, and J. Fedor* \\ Department of Chemistry, University of Fribourg, Chemin du Musée 9, CH-1700 Fribourg, Switzerland
}

\begin{abstract}
We have measured absolute dissociative electron attachment (DEA) cross sections in methylacetylene (propyne, $\mathrm{C}_{3} \mathrm{H}_{4}$ ) and dimethylacetylene (but-2-yne, $\mathrm{C}_{4} \mathrm{H}_{6}$ ). The main feature in the low-energy DEA spectrum is a $\pi^{*}$ shape resonance giving rise to fragments at $3.4 \mathrm{eV}$ in $\mathrm{C}_{3} \mathrm{H}_{4}$ and $4.0 \mathrm{eV}$ in $\mathrm{C}_{4} \mathrm{H}_{6}$. The process $\mathrm{C}_{3} \mathrm{H}_{4}+e \rightarrow \mathrm{C}_{3} \mathrm{H}_{3}^{-}+\mathrm{H}$ proceeds via abstraction of the acetylenic hydrogen which is mediated by effective vibronic coupling. The abstraction of methyl group hydrogen, which does not require symmetry lowering of the transient negative ion, was not observed; the spatial separation of the bond from the resonance decreases the cross section dramatically. The presence of the methyl group further influences the DEA cross sections via change of the resonance's position and via blocking one or both of the DEA active sites in acetylene. No cleavage of the C-methyl bond has been observed, and reasons for this effect are discussed. Additionally, several higher-lying resonances (6 to $15 \mathrm{eV})$ leading to production of an $\mathrm{H}^{-}$fragment were observed and assigned.
\end{abstract}

\section{INTRODUCTION}

Methylacetylene (propyne, $\mathrm{H}-\mathrm{C} \equiv \mathrm{C}-\mathrm{CH}_{3}$ ) and dimethylacetylene (but-2-yne, $\mathrm{CH}_{3}-\mathrm{C} \equiv \mathrm{C}-\mathrm{CH}_{3}$ ) are derivatives of acetylene $(\mathrm{H}-\mathrm{C} \equiv \mathrm{C}-\mathrm{H})$. Acetylene was shown to be a prototype molecule in which the dissociative electron attachment (DEA) proceeds via electron capture in a $\pi^{*}$ orbital and the dissociation is mediated via vibronic coupling. Such molecules are the subject of current interest both experimentally [1-4] and theoretically [5-8], since the dynamical situation is more complicated than in the molecules where the DEA proceeds via electron capture to a $\sigma^{*}$ orbital and direct cleavage of the involved bond. For some molecules - a notable example is formic acid $[9,10]$ - there is an ongoing discussion as to which of the two processes is operative. Methylacetylene presents an opportunity to study both processes in one molecule: the dissociation of the acetylenic $\mathrm{C}-\mathrm{H}$ bond can be mediated only via vibronic coupling and symmetry lowering, whereas the abstraction of methyl hydrogens is not symmetry forbidden and can proceed directly.

In all these cases DEA is a resonant process: first, a temporary negative ion (resonance) is formed via vertical attachment of the electron to the molecule. This either dissociates or undergoes electron detachment. In acetylene the $\pi^{*}$ shape resonance located at $2.6 \mathrm{eV}$ gives rise to the $\mathrm{C}_{2} \mathrm{H}^{-}+\mathrm{H}$ dissociation channel just above the energetic threshold [1]. This dissociation into ground-state fragments is symmetry forbidden in linear geometry and the $\mathrm{H}$ atom follows an out-of-line trajectory as the bond stretches [5]. Such behavior, where the resonant state cannot dissociate in original geometry and distorts during the fragmentation, has been seen in a handful of molecules, for instance $\mathrm{C}_{2} \mathrm{H}_{2}$ [1,5], $\mathrm{C}_{4} \mathrm{H}_{2}$ [2,3], $\mathrm{HCCCN}$ [4], and chlorobenzene [11]. A related case is $\mathrm{HCN}$ [7,12], where the outgoing $\mathrm{H}$ atom tunnels through the barrier with symmetry lowering playing a limited role.

In methylacetylene, the presence of hydrogens from the methyl group opens a competition between fragmentation

*juraj.fedor@unifr.ch sites. For the acetylenic $\mathrm{C}-\mathrm{H}$ bond cleavage, the situation is analogous to that in acetylene-the $\pi^{*}$ orbital into which the electron is captured is antisymmetric with respect to the plane containing the $\mathrm{C}-\mathrm{H}$ bond, the acetylenic $\mathrm{C}-\mathrm{H} \sigma^{*}$ orbital is symmetric, and the dissociation is mediated via an out-of-plane vibration. On the other hand, the methyl group $\mathrm{C}-\mathrm{H}$ bonds are rotated out of the symmetry axis and thus permit direct coupling of their $\sigma^{*}$ orbitals with the resonant $\pi^{*}$ orbital. However, the $\pi^{*}$ state is centered on the $\mathrm{C} \equiv \mathrm{C}$ bond and the methyl $\mathrm{C}-\mathrm{H}$ bonds are spatially more distant. This fundamental question of which effect prevails-the symmetry or the spatial proximity - is the main motivation for the present study.

Furthermore, the presence of the methyl group raises the question whether the $\mathrm{C}-\mathrm{CH}_{3}$ bond is cleaved as well. Methylation was used to block the active DEA site in uracil and thymine $[13,14]$; however, the mechanism of this blocking is not clear. The suppression of the DEA signal due to methylation was seen also for Feshbach resonances [15] where it was assigned to the emergence of an activation barrier. This question is raised also in dimethylacetylene where both hydrogens of the acetylene molecule are replaced by methyl groups.

The interest in electron collisions with these molecules is not purely academic. Methylacetylene (and to some extent also dimethylacetylene) occurs in environments where collisions with free electrons play an important role in inducing chemistry. For example, it has been detected in interstellar clouds [16] and carbon-rich circumstellar envelopes [17]—-these environments are characterized by single collision conditions and low temperatures, and collisions with free electrons play an important role. Methylacetylene is also an important intermediate in combustion and flames [18] since it serves as a precursor for the propargyl radical, which reacts with itself and forms cyclic species [19] (benzene, the phenyl radical, and more complicated polyaromatic hydrocarbons).

Early studies of resonant electron collisions with methylacetylene by Flicker et al. [20], Dance and Walker [21], and van Veen and Plantenga [22] focused on electron energyloss spectroscopy and identified vibrational excitation of the ground-state molecule via $\pi^{*}$ shape resonance around $3-\mathrm{eV}$ 
incident electron energy. Dance and Walker [21] detected this shape resonance also in dimethylacetylene at $3.6 \mathrm{eV}$. More recent studies of Palmer and Walker [23,24] focused on excited electronic states of these molecules by means of electron energy-loss spectroscopy and vacuum ultraviolet (vuv) absorption spectroscopy. The most comprehensive study of low-energy electron scattering from methylacetylene was presented by Tanaka and co-workers [25], who measured differential cross sections for elastic scattering and vibrational excitation. They observed two resonances, the $\pi^{*}$ shape resonance at $3.2 \mathrm{eV}$ and a broad resonance centered at $7.5 \mathrm{eV}$ which is due to a capture of the electron in the $\sigma^{*}$ antibonding orbital of the $\mathrm{C}-\mathrm{H}$ bond.

In this paper, we present absolute cross sections for DEA to methylacetylene and dimethylacetylene and discuss the abovementioned issues.

\section{EXPERIMENT}

The quantitative DEA spectrometer has been described in detail previously $[1,26]$ and only minor improvements were introduced in the course of this work. The electron beam is produced by a trochoidal electron monochromator, passed through a collision cell filled with the sample gas and collected by a Faraday cup. Anions created by DEA are extracted through a narrow slit in the cell's wall to a time-of-flight mass spectrometer. The time-of-flight tube is constructed as a focusing ion lens and the entire setup was designed to keep the extraction and detection efficiency independent of the mass and initial kinetic energy of the detected anions. The whole experiment is pulsed-the electron beam passes through the collision cell during $200 \mathrm{~ns}$ while the cell is field free, and after another $200 \mathrm{~ns}$ (so that the electrons are allowed to leave the cell) a voltage pulse of $-300 \mathrm{~V}$ is applied across the cell to extract the anions. The anions are detected by a microchannel plate coupled with a phosphorus screen and a photomultiplier, counted, and their arrival times are analyzed using a delayed coincidence scheme.

The pressure in the collision cell is controlled by a needle valve and monitored by a capacitance manometer. It was kept in the range $3 \times 10^{-4}$ to $6 \times 10^{-4}$ Torr. The electron energy resolution during the present measurements was $250 \mathrm{meV}$.

The methylacetylene sample (gaseous at standard laboratory conditions) was kept in a glass tube at the temperature of dry ice $\left(-78.5^{\circ} \mathrm{C}\right)$ during measurements. Under these conditions it is a liquid with a sufficiently high vapor pressure. Dimethylacetylene (liquid at standard laboratory conditions) was kept in a glass tube immersed in ethylene glycol cooled down to $-22^{\circ} \mathrm{C}$. Keeping the samples at low temperatures increased the purity of the sample, since it lowered the partial vapor pressure of impurities with substantially different volatilities. This concerns mainly water, which upon DEA yields $\mathrm{H}^{-}$ anions at similar energies as the present samples [27].

Absolute magnitudes of the cross sections were calibrated on the 4.4-eV peak of $\mathrm{O}^{-}$from $\mathrm{CO}_{2}$ with a peak cross-section value of $14 \mathrm{pm}^{2}$ [26]. The error of the absolute measurements (two standard deviations) is taken to be $\pm 25 \%$. This is the combined error of $\pm 20 \%$ of the relative measurements with the $\pm 15 \%$ error of the $\mathrm{O}^{-}$from $\mathrm{CO}_{2}$ absolute cross section.

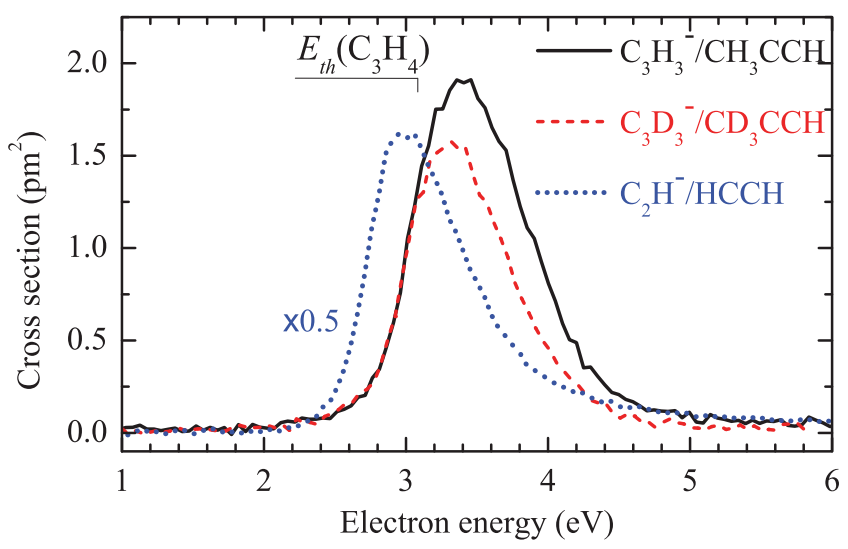

FIG. 1. (Color online) DEA cross sections for the abstraction of an $\mathrm{H}$ atom in methylacetylene and partially deuterated methylacetylene. The cross section of acetylene from Ref. [1] is shown for comparison, multiplied by one half.

\section{RESULTS AND DISCUSSION}

Figures 1 and 2 show the cross sections for "heavy" $\left(\mathrm{C}_{3} \mathrm{H}_{3}{ }^{-}\right.$, $\left.\mathrm{C}_{3} \mathrm{D}_{3}^{-}\right)$and "light" $\left(\mathrm{H}^{-}\right.$and $\left.\mathrm{D}^{-}\right)$fragments following DEA to methylacetylene, partially deuterated methylacetylene, and dimethylacetylene. No heavy fragments were observed for the latter molecule. The heavy fragments peak at 3.3 and $3.4 \mathrm{eV}$ (nondeuterated and deuterated methylacetylene, respectively), an energy region dominated by the $\pi^{*}$ shape resonance. The
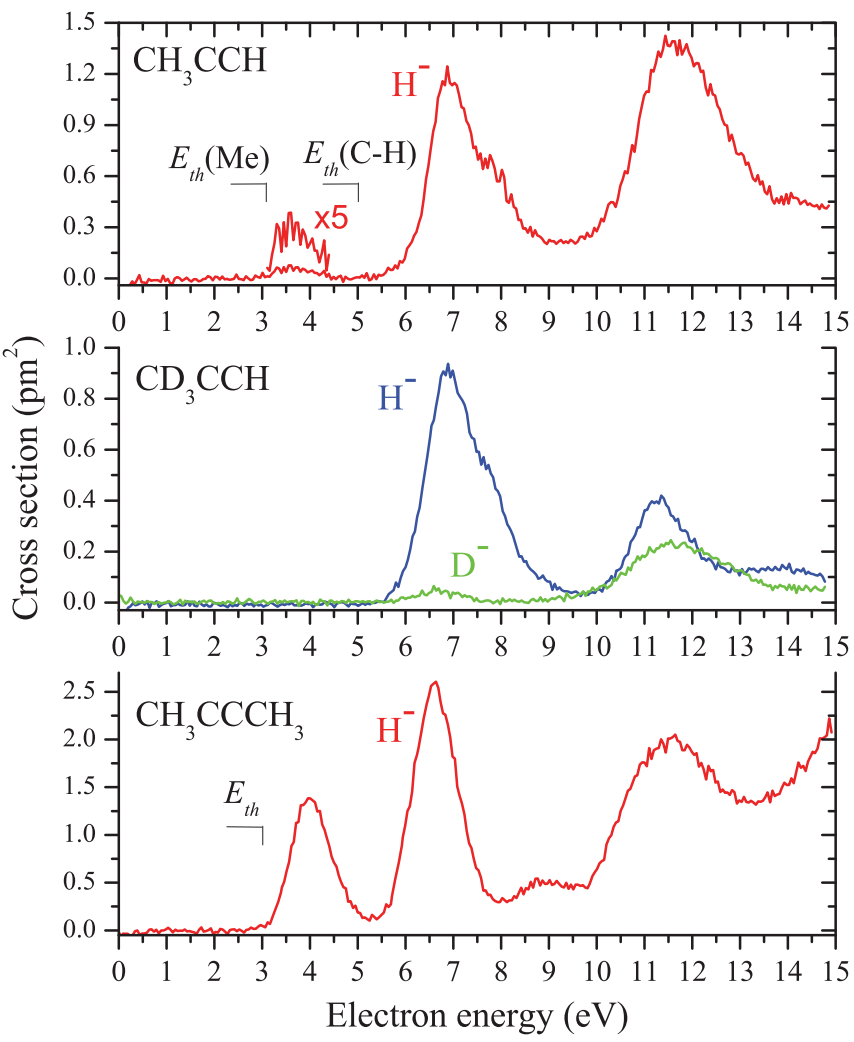

FIG. 2. (Color online) Cross sections for production of $\mathrm{H}^{-}$and $\mathrm{D}^{-}$fragments. The two threshold energies shown on the top panel correspond to $\mathrm{H}^{-}$abstracted either from the methyl group or the terminal $\mathrm{C}-\mathrm{H}$ bond of methylacetylene. 
TABLE I. Threshold energies (in eV).

\begin{tabular}{llcl}
\hline \hline Target & \multicolumn{1}{c}{ Products } & Calc. $^{a}$ & Expt. $^{\text {b }}$ \\
\hline $\mathrm{HCCCH}_{3}$ & $\mathrm{CCCH}_{3}^{-}+\mathrm{H}$ & 2.90 & 3.17 \\
& $\mathrm{HCCCH}_{2}^{-}+\mathrm{H}$ & 2.76 & 2.96 \\
& $\mathrm{CCH}^{-}+\mathrm{CH}_{3}$ & 2.22 & 2.4 \\
& $\mathrm{H}^{-}+\mathrm{CCCH}_{3}$ & 4.86 & 5.13 \\
& $\mathrm{H}^{-}+\mathrm{HCCCH}_{2}$ & 2.86 & 3.10 \\
$\mathrm{CH}_{3} \mathrm{CCCH}_{3}$ & $\mathrm{H}^{-}+\mathrm{CH}_{3} \mathrm{CCCH}_{2}$ & 2.8 & 3.03 \\
& $\mathrm{CH}_{3} \mathrm{CC}^{-}+\mathrm{CH}_{3}$ & 2.43 & 2.54 \\
$\mathrm{HCCH}$ & $\mathrm{CCH}^{-}$ & 2.70 & 2.744 \\
\hline \hline
\end{tabular}

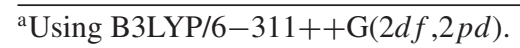

${ }^{\mathrm{b}}$ The bond dissociation energies were taken from Ref. [28] and references therein and the electron affinities $E_{a}\left(\mathrm{C}_{3} \mathrm{H}_{3}\right)$ from Ref. [29], $E_{a}\left(\mathrm{HCCCH}_{2}\right)$ from Ref. [30], $E_{a}\left(\mathrm{C}_{2} \mathrm{H}\right)$ from Ref. [31], and $E_{a}(\mathrm{H})$ from Ref. [32].

$\mathrm{H}^{-}$and $\mathrm{D}^{-}$fragments are found also at higher electron energies. Table I summarizes threshold energies for the appearance of the individual fragments. Since we work at single collision conditions, they were calculated from bond dissociation energies and electron affinities (rather than from enthalpies of formation). The experimental threshold energies were amended by density functional theory (DFT) calculations at the $\mathrm{B} 3 \mathrm{LYP} / 6-311++\mathrm{G}(2 d f, 2 p d)$ level of theory. The good agreement between the DFT threshold energies and values derived from the literature experimental data confirms the previous conclusion about the reliability of this method and basis set $[33,34]$.

One interesting fact in Table $\mathrm{I}$ is a $2-\mathrm{eV}$ difference in threshold energies for production of $\mathrm{H}^{-}$when abstracted from the acetylenic or methyl site. On the other hand, when the neutral hydrogen is abstracted, the threshold energies for these two sites differ only by $0.14 \mathrm{eV}$. This suggests that the neutral radicals formed after $\mathrm{H}^{-}$abstraction from the two sites have very different electronic energies (since H-atom affinity is constant), whereas the heavy anions formed after $\mathrm{H}$-atom abstraction have very similar electronic energies. This is indeed a known fact - the propargyl radical $\mathrm{HCCCH}_{2}$ is by approximately $2 \mathrm{eV}$ more stable than the propynyl radical $\mathrm{CCCH}_{3}$; the stabilization is provided by its planar geometry [35]. However, the addition of an electron and formation of the propargyl anion $\mathrm{HCCCH}_{2}^{-}$leads to the geometry distortion, and this anion is energetically very close to the propynyl anion $\left(\mathrm{CCCH}_{3}^{-}\right)$[36], which explains the similar threshold energies for $\mathrm{H}$-atom abstraction.

For the discussion of the origin of the resonances, it is helpful to review the electronic structure of the two molecules. Methylacetylene in its ground state has a $\mathrm{C}_{3 v}$ symmetry, and the electronic configuration is ... $\left(4 a_{1}\right)^{2}\left(5 a_{1}\right)^{2}\left(6 a_{1}\right)^{2}(1 e)^{4}(2 e)^{4}$ [37]. The lowest unoccupied molecular orbital (LUMO) is of $3 e$ symmetry and is a $\pi^{*}$ orbital centered on the $\mathrm{C} \equiv \mathrm{C}$ bond. The $3-\mathrm{eV}$ resonance corresponds to a temporary capture of the incoming electron into this orbital. The lowestenergy structure of dimethylacetylene has $\mathrm{D}_{3 h}$ symmetry (eclipsed geometry); the corresponding electron configuration is $\left(3 a_{1}^{\prime}\right)^{2}\left(3 a_{2}^{\prime \prime}\right)^{2}\left(4 a_{1}^{\prime}\right)^{2}\left(4 a_{2}^{\prime \prime}\right)^{2}\left(1 e^{\prime}\right)^{4}\left(1 e^{\prime \prime}\right)^{4}\left(5 a_{1}^{\prime}\right)^{2}\left(2 e^{\prime}\right)^{4}$ [24]. The virtual orbital giving rise to the $\pi^{*}$ shape resonance in methylacetylene is the $2 e^{\prime \prime}$ LUMO.

\section{A. Region of the $\pi^{*}$ shape resonance}

The $\pi^{*}$ shape resonance has been reported in electronscattering experiments for all molecules studied. It is centered at $2.6 \mathrm{eV}$ in acetylene [38], at $3.0 \mathrm{eV}$ in methylacetylene [21,23] (at $3.2 \mathrm{eV}$ in Ref. [25]), and at $3.6 \mathrm{eV}$ in dimethylacetylene [21,23].

In DEA to methylacetylene, this resonance dissociates mainly via abstraction of the neutral $\mathrm{H}$ atom, leading to the $\mathrm{C}_{3} \mathrm{H}_{3}^{-}$anionic fragment. The peak cross section is $1.9 \mathrm{pm}^{2}$, about half that of acetylene (see Table II). At this energy, the DEA to the precursor molecule partially deuterated on the methyl group yields $\mathrm{C}_{3} \mathrm{D}_{3}^{-}$with the peak cross section being $1.58 \mathrm{pm}^{2}$. Thus, the $\mathrm{H}$ atom is lost via cleavage of the acetylenic $\mathrm{C}-\mathrm{H}$ bond and not from the methyl group.

There is a seeming possibility that the hydrogen abstraction from the methyl group does happen but the $\mathrm{CD}_{2} \mathrm{CCH}^{-}$signal in partially deuterated methylacetylene is suppressed due to a strong isotope effect. The outgoing D atom moves slower and the increase in dissociation time can suppress the DEA channel in favor of vibrational excitation. However, the difference in cross section of the nondeuterated and deuterated precursors is smaller than the experimental error and is probably not significant. Thus, the contribution of the methylic $\mathrm{H}$-atom abstraction to the $\mathrm{C}_{3} \mathrm{H}_{3}^{-}$from $\mathrm{C}_{3} \mathrm{H}_{4}$ signal is very small. The deuteration on the methyl site is not expected to affect the cross section for the cleavage of the acetylenic $\mathrm{C}-\mathrm{H}$ bond since the difference in reduced mass between the $\mathrm{CH}_{3} \mathrm{CC}^{-}-\mathrm{H}$ and $\mathrm{CD}_{3} \mathrm{CC}^{-}-\mathrm{H}$ systems is only $0.15 \%$ and the corresponding difference in dissociation time is too small to significantly influence the competition between dissociation and autodetachment. We conclude that the vast majority of the $\mathrm{H}$-atom abstraction is indeed happening on the acetylenic site.

The symmetry situation of the two available methylacetylenes' DEA sites is demonstrated by the schematic of its LUMO in Fig. 3. The $\pi^{*}$ LUMO of acetylene is shown for comparison. The shape resonance responsible for DEA originates from the electron capture into this virtual orbital. Even though the virtual orbital is not an accurate representation of

TABLE II. Fragment ion cross sections. The standard error of the measurement is $\pm 25 \%$.

\begin{tabular}{lccc}
\hline \hline Target & Ion & El. energy $(\mathrm{eV})$ & Peak cross section $\left(\mathrm{pm}^{2}\right)$ \\
\hline $\mathrm{HCCCH}_{3}$ & $\mathrm{C}_{3} \mathrm{H}_{3}^{-}$ & 3.4 & 1.90 \\
& $\mathrm{H}^{-}$ & 3.6 & $0.06^{\mathrm{a}}$ \\
& & 6.9 & 1.21 \\
& & 11.6 & 1.40 \\
$\mathrm{HCCCD}_{3}$ & $\mathrm{C}_{3} \mathrm{D}_{3}^{-}$ & 3.3 & 1.57 \\
& $\mathrm{H}^{-}$ & 6.9 & 0.92 \\
& & 11.3 & 0.42 \\
& $\mathrm{D}^{-}$ & 6.6 & 0.05 \\
& & 11.6 & 0.23 \\
$\mathrm{CH}_{3} \mathrm{CCCH}_{3}$ & $\mathrm{H}^{-}$ & 4.0 & 1.38 \\
& & 6.6 & 2.61 \\
& & 8.8 & 0.50 \\
& & 11.6 & 2.00 \\
\hline \hline
\end{tabular}

${ }^{a}$ Due to low signal-to-noise ratio this value has a larger estimated error bar than other cross sections, approximately $\pm 30 \%$ (noise-introduced error of $\pm 20 \%$ combined with our standard error of $\pm 25 \%$ ). 
(a)

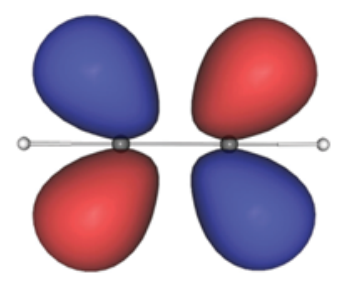

(b)

FIG. 3. (Color online) The $\pi^{*}$ LUMO of (a) acetylene and (b) methylacetylene. Drawn with program MOLEKEL [39].

the actual resonant wave function, it qualitatively illustrates its symmetry and general shape. The methylacetylene's LUMO has no coefficient on the acetylenic hydrogen and the anion state is not directly dissociative along this $\mathrm{C}-\mathrm{H}$ bond. The path towards dissociation is provided by symmetry lowering (an out-of-linearity bend of dissociating hydrogen) and $\pi^{*} / \sigma^{*}$ coupling. On the other hand, the LUMO conjugates with the $\sigma^{*}$ orbital of the methylic $\mathrm{C}-\mathrm{H}$ bond and the resonant state is directly dissociative along this bond. However, the methylic $\mathrm{C}-\mathrm{H}$ bond is spatially more distant from the $\mathrm{C} \equiv \mathrm{C}$ bond on which the $\pi^{*}$ orbital is centered.

The experimental observation shows the cleavage of the acetylenic $\mathrm{C}-\mathrm{H}$ bond. This suggests high effectivity of the vibronic coupling and shows that the proximity prevails above the symmetry restrictions. Buillard et al. [40] investigated similar situation in dihalotoluenes, where an electron is captured into a $\pi^{*}$ orbital of phenyl moiety and two C-halogen bonds are available, one closer to the ring but with symmetry forbidden cleavage and the other separated by a methylene group with symmetry allowed cleavage. Interestingly, they observed the opposite effect as we do in the present case: the more distant bond was cleaved much more effectively than the closer, symmetry restricted bond. However, in the case of dihalotoluenes the threshold energy for cleavage of the more distant $\mathrm{C}$-halogen bond is considerably lower than that of the closer one. In the present case, the threshold energies of the two sites are very similar (Table I). This may reverse the intramolecular competition in dihalotoluenes in favor of the symmetry allowed dissociation.

The $\mathrm{C}_{3} \mathrm{H}_{3}^{-}$cross section in methylacetylene is approximately half of that of the corresponding cross section for the $\mathrm{C}_{2} \mathrm{H}^{-}+\mathrm{H}$ channel in acetylene $\left(3.45 \mathrm{pm}^{2}\right.$ when measured with the present method [1] or $3.8 \mathrm{pm}^{2}$ when measured with the total ion collection method [2]). The $\pi^{*}$ shape resonance in acetylene lies at $2.6 \mathrm{eV}$ (as seen in vibrational excitation spectra) and the threshold for this DEA channel is $2.74 \mathrm{eV}$. In methylacetylene the resonance is centered around $3.2 \mathrm{eV}$ and the DEA threshold is at $3.17 \mathrm{eV}$. It is a general rule (e.g., Refs. [41,42]), that shape resonances that lie higher in energy have larger autodetachment widths and correspondingly lower DEA cross sections. Another possible contribution to cross-section lowering is the lower symmetry of the methylacetylene's resonant state which contains lower partial waves than that of acetylene (which couples to the $d$ wave). The lower partial wave has a smaller centrifugal barrier and thus increases the probability of electron "leaking out" and enhancing the autodetachment channel. The comparison of cross sections in acetylene and methylacetylene can be further influenced by the different effectivity of vibronic coupling, which is determined by the shape of individual vibrational wave functions.

The second dissociative channel of the $\pi^{*}$ shape resonance in methylacetylene is the abstraction of the $\mathrm{H}^{-}$anion (the top panel of Fig. 2). The corresponding peak cross section is $0.06 \mathrm{pm}^{2}$. Since the threshold energy for the hydrogen abstraction from the terminal $\mathrm{C}-\mathrm{H}$ bond is $5.13 \mathrm{eV}$, the abstracted hydrogen has to come from the methyl group. Upon deuteration on the methyl group, the cross section on this channel drops below the detection level probably due to strong isotope effect.

There was no cleavage of the carbon-methyl group detected that would lead to the eventual $\mathrm{C}_{2} \mathrm{H}^{-}$fragment. This channel is energetically favourable - the threshold energy is $2.22 \mathrm{eV}$ (Table I), which is even lower than thresholds for the observed dissociative processes. There are two possible effects contributing to the absence of this channel. One would be the barrier on the potential-energy surface of the $\mathrm{C}_{2} \mathrm{H}^{-}+\mathrm{CH}_{3}$ dissociation pathway. Such a barrier has been proposed for the Feshbach resonance in ethyl methyl ether [15] since it was found on the potential-energy surface of its parent Rydberg state. To verify this option in methylacetylene one would need to perform fixed nuclei scattering calculations at several geometries of the dissociating fragments. The second contribution to the absence of this channel is dynamical-the high mass of the methyl group leads to a long dissociation time and causes strong increase in the autodetachment channel and suppression of the DEA channel.

Dimethylacetylene has both acetylenic hydrogens replaced by methyl groups, and the $\pi^{*}$ resonance relaxes exclusively via dissociation towards the $\mathrm{H}^{-}$channel-no heavier fragments were observed. The two methyl groups shift the resonance to a higher energy - the $\mathrm{H}^{-}$signal peaks at $4.0 \mathrm{eV}$. The resonance has been detected previously in an electron transmission experiment at $3.6 \mathrm{eV}$ [24].

\section{B. Higher-lying resonances}

Resonances in the region 5-15 eV decay exclusively via expulsion of the $\mathrm{H}^{-}$ion. For both compounds, the spectra are dominated by two pronounced peaks at 6.9 and $11.6 \mathrm{eV}$ for methylacetylene and 6.6, 8.8, and $11.6 \mathrm{eV}$ for dimethylacetylene. Additionally, the 6.9-eV methylacetylene peak has a shoulder which suggests presence of a second, unresolved peak around $7.8 \mathrm{eV}$. Interestingly, in partially deuterated methylacetylene, there are both $\mathrm{H}^{-}$and $\mathrm{D}^{-}$fragments appearing at the energies of both resonances, which means that the involved temporary negative ion states are dissociative along $\mathrm{C}-\mathrm{H}$ coordinates both of the acetylenic and methyl group hydrogens. The high-energy tail of the spectra is superimposed on a slowly rising continuous background which most probably originates from ion-pair formation.

In the vibrational excitation spectrum of methylacetylene, this range of energies is dominated by a broad resonance centered around $7.5 \mathrm{eV}$ [25]. Such a resonance has been observed in a variety of hydrocarbons $[43,44]$ and is due to a capture of the electron in $\sigma^{*}$ antibonding orbitals of the $\mathrm{C}-\mathrm{H}$ bonds. However, this resonance is not expected to give rise to a DEA signal because of its large width and correspondingly short autodetachment lifetime. 
More probably, the origins of the peaks are Feshbach or core-excited shape resonances with double occupation of Rydberg orbitals and a ground-state positive ion core. These resonances can be identified via comparison with their parent states (Rydberg states in the vuv electronic spectrum of precursor molecules) or their grandparent states which are revealed by uv photoelectron spectra. Adding an electron into a Rydberg orbital around a positive ion core releases about $4 \mathrm{eV}$ of energy. Another approximately $0.4 \mathrm{eV}$ is released when a second electron is added to a $3 s$ Rydberg orbital. Even though the diffuse Rydberg electron cloud interacts only weakly with the core, the relation between photoelectron spectra and Feshbach resonant states is dependent on the target molecule due to eventual penetration of bulky substituents into the Rydberg orbital [33]. Thus the energy shift between the peaks in the DEA and photoelectron spectra is dependent on the target molecule. The He(I) photoelectron spectrum of methylacetylene [45] shows four main bands with ionization energies of $10.37,14.7,15.3$, and $17.5 \mathrm{eV}$, corresponding to ionization of electrons from $2 e, 1 e, 7 a_{1}$, and $6 a_{1}$ orbitals, respectively. It should be noted that the last three photoelectron peaks are superimposed into one broad band. At any rate, if the photoelectron spectrum is shifted by $3.4 \mathrm{eV}$, its $2 e^{-1}$ and $1 e^{-1}$ positions reasonably overlap with the 6.9- and 11.6-eV bands in the $\mathrm{H}^{-}$DEA spectrum. Thus the most probable assignment of these two bands is to $(2 e)^{-1}(1 s)^{2}(6.9 \mathrm{eV})$ and $(1 e)^{-1}(1 s)^{2}$ $(11.6 \mathrm{eV})$ Feshbach resonances.

In dimethylacetylene, the ionization energies are 9.59, 14.3, $14.9,15.3$, and $16.3 \mathrm{eV}$, corresponding to the ionization of the $2 e^{\prime}, 5 a_{1}^{\prime}, 1 e^{\prime \prime}, 1 e^{\prime}$, and $4 a_{2}^{\prime \prime}$ orbitals, respectively [24,46]. Except for the first peak, the ionization energies again coalesce into a single broad band. Upon a shift of $3 \mathrm{eV}$, our 6.6-eV DEA peak overlaps with the position of the $\left(2 e^{\prime}\right)^{-1}$ photoelectron spectroscopy (PES) band and the 11.5-eV DEA peak with the $\left(5 a_{1}^{\prime}\right)^{-1}$ PES band. This leads to an assignment of these two DEA bands as holes in the corresponding orbitals and an electron pair in an $s$-type Rydberg orbital.

\section{CONCLUSIONS}

We have experimentally probed the intramolecular competition between the two DEA mechanisms which arise in the region methylacetylene's $\pi^{*}$ resonance. It is the acetylenic $\mathrm{C}-\mathrm{H}$ bond that is cleaved to produce the anionic fragment and neutral $\mathrm{H}$ atom. Thus the spacial proximity of this bond to the resonance centered on the $\mathrm{C} \equiv \mathrm{C}$ bond prevails upon the fact that this dissociation has to be accompanied by symmetry lowering of the transient negative ion, in contrast to the spatially more distant methyl $\mathrm{C}-\mathrm{H}$ bond where this symmetry restriction does not apply.

The cross section for acetylenic $\mathrm{C}-\mathrm{H}$ dissociation in methylacetylene is two times smaller than that of acetylene-not a large difference in view of the steep dependence of DEA cross sections upon resonance width. The drop of the cross section could be due to higher resonance energy and/or lower symmetry permitting lower partial waves in the decay; it could be also influenced by the different effectivity of vibronic coupling.

No cleavage of the C-methyl bond has been detected in either methylacetylene or dimethylacetylene. In the latter molecule the only DEA product is the $\mathrm{H}^{-}$anion. The methyl group thus serves as a protective group with respect to the DEA. However, this is not due to energetic reasons since the threshold energy for cleaving the $\mathrm{C}$-methyl bond is even lower than that for cleaving $\mathrm{C}-\mathrm{H}$ bonds. One possible contributing factor is a barrier with respect to methyl group dissociation which is not present in the acetylenic $\mathrm{C}-\mathrm{H}$ bond potential surface. The second possible contributing factor is dynamical and results from the competition between the DEA and autodetachment channels.

The DEA spectra at higher electron energies are dominated by Feshbach resonances leading to formation of $\mathrm{H}^{-}$anions.

\section{ACKNOWLEDGMENT}

This work is part of Project No. PZ00P2_132357/1 of the Swiss National Science Foundation.
[1] O. May, J. Fedor, and M. Allan, Phys. Rev. A 80, 012706 (2009).

[2] O. May, J. Fedor, B. C. Ibănescu, and M. Allan, Phys. Rev. A 77, 040701(R) (2008).

[3] M. Allan, O. May, J. Fedor, B. C. Ibănescu, and L. Andric, Phys. Rev. A 83, 052701 (2011).

[4] K. Graupner, T. L. Merrigan, T. A. Field, T. G. A. Youngs, and P. C. Marr, New J. Phys. 8, 117 (2006).

[5] S. T. Chourou and A. E. Orel, Phys. Rev. A 77, 042709 (2008).

[6] S. T. Chourou and A. E. Orel, Phys. Rev. A 80, 034701 (2009).

[7] S. T. Chourou and A. E. Orel, Phys. Rev. A 80, 032709 (2009).

[8] S. T. Chourou and A. E. Orel, Phys. Rev. A 83, 032709 (2011).

[9] T. N. Rescigno, C. S. Trevisan, and A. E. Orel, Phys. Rev. Lett. 96, 213201 (2006).

[10] G. A. Gallup, P. D. Burrow, and I. I. Fabrikant, Phys. Rev. A 79, 042701 (2009).

[11] T. Skalicky, C. Chollet, N. Pasquier, and M. Allan, Phys. Chem. Chem. Phys. 4, 3583 (2002).
[12] O. May, D. Kubala, and M. Allan, Phys. Rev. A 82, 010701(R) (2010).

[13] P. D. Burrow, G. A. Gallup, A. M. Scheer, S. Denifl, S. Ptasinska, T. Märk, and P. Scheier, J. Chem. Phys. 124, 124310 (2006).

[14] S. Ptasinska, S. Denifl, V. Grill, T. D. Märk, E. Illenberger, and P. Scheier, Phys. Rev. Lett. 95, 093201 (2005).

[15] B. C. Ibanescu and M. Allan, Phys. Chem. Chem. Phys. 34, 5234 (2008).

[16] M. J. McEwan, G. B. I. Scott, N. G. Adams, L. M. Babcock, R. Terzieva, and E. Herbst, Astrophys. J. 513, 287 (1999).

[17] M. Agundez, J. P. Fonfria, J. Cernicharo, J. R. Pardo, and M. Guelin, Astron. Astrophys. 479, 493 (2008).

[18] N. Hansen, J. A. Miller, P. R. Westmoreland, T. Kasper, K. Kohse-Höinghaus, J. Wang, and T. A. Cool, Combustion and Flame 156, 2153 (2009).

[19] J. A. Miller and S. J. Klippenstein, J. Phys. Chem. A 107, 2680 (2003). 
[20] W. M. Flicker, O. A. Mosher, and A. Kuppermann, J. Chem. Phys. 69, 3311 (1978).

[21] D. F. Dance and I. C. Walker, J. Chem. Soc., Faraday Trans 70, 365 (1974).

[22] E. van Veen and F. Plantenga, Chem. Phys. Lett. 38, 493 (1976).

[23] M. H. Palmer, C. C. Ballard, and I. C. Walker, Chem. Phys. 249, 129 (1999).

[24] M. H. Palmer and I. C. Walker, Chem. Phys. 340, 158 (2007).

[25] Y. Nakano, M. Hoshino, M. Kitajima, H. Tanaka, and M. Kimura, Phys. Rev. A 66, 032714 (2002).

[26] J. Fedor, O. May, and M. Allan, Phys. Rev. A 78, 032701 (2008).

[27] J. Fedor et al., J. Phys. B: Atom. Molec. Phys. 39, 3935 (2006).

[28] Y.-R. Luo, Handbook of Bond Dissociation Energies in Organic Compounds (CRC, Boca Raton, 2003).

[29] M. S. Robinson, M. L. Polak, V. M. Bierbaum, C. H. DePuy, and W. C. Lineberger, J. Am. Chem. Soc. 117, 6766 (1995).

[30] J. M. Oakes and G. B. Ellison, J. Am. Chem. Soc. 105, 2959 (1983).

[31] Y. Shi and K. M. Ervin, Chem. Phys. Lett. 318, 149 (2000).

[32] K. R. Lykke, K. K. Murray, and W. C. Lineberger, Phys. Rev. A 43, 6104 (1991).

[33] B. C. Ibanescu, O. May, A. Monney, and M. Allan, Phys. Chem. Chem. Phys. 9, 3163 (2007).
[34] B. C. Ibanescu and M. Allan, Phys. Chem. Chem. Phys. 11, 7640 (2009).

[35] T. L. Nguyen, A. M. Mebel, and R. I. Kaiser, J. Phys. Chem. A 105, 3284 (2001).

[36] P. E. Crider, L. Castiglioni, K. E. Kautzman, and D. M. Neumark, J. Chem. Phys. 130, 044310 (2009).

[37] G. H. Ho, M. S. Lin, Y. L. Wang, and T. W. Chang, J. Chem. Phys. 109, 5868 (1998).

[38] R. Dressler and M. Allan, J. Chem. Phys. 87, 4510 (1987).

[39] U. Varetto, computer program MOLEKEL 5.4, Swiss National Supercomputing Centre, Lugano, Switzerland (2009).

[40] C. Buillard, M. Allan, and E. Haselbach, J. Phys. Chem. 98, 11040 (1994).

[41] G. A. Gallup, K. Aflatooni, and P. D. Burrow, J. Chem. Phys. 118, 2562 (2003).

[42] K. Aflatooni and P. D. Burrow, J. Chem. Phys. 113, 1455 (2000).

[43] R. Čurík, P. Čársky, and M. Allan, J. Phys. B: Atom. Molec. Phys. 41, 115203 (2008).

[44] M. Allan and L. Andric, J. Chem. Phys. 105, 3559 (1996).

[45] K. Kimura, S. Katsumata, Y. Achiba, T. Yamazaki, and S. Iwata, Handbook of HeI Photoelectron Spectra of Fundamental Organic Molecules (Japan Scientific Societies, Tokyo, 1981).

[46] G. Bieri, F. Burger, E. Heilbronner, and J. P. Maier, Helv. Chim. Acta 60, 2213 (1977). 